\title{
X-RAY PHOTOELECTRON SPECTROSCOPY OF FERROELECTRIC SEMICONDUCTOR SbSI CRYSTALS
}

\author{
J. Grigas ${ }^{\text {a }}$, E. Talik ${ }^{\mathrm{b}}$, and V. Lazauskas ${ }^{\mathrm{c}}$ \\ ${ }^{a}$ Faculty of Physics, Vilnius University, Saulètekio 9, LT-10222 Vilnius, Lithuania \\ E-mail: jonas.grigas@ff.vu.lt \\ ${ }^{\mathrm{b}}$ Institute of Physics, Silesian University, Universytetska 4, 40-007 Katowice, Poland \\ ${ }^{\mathrm{c}}$ Vilnius University Research Institute of Theoretical Physics and Astronomy, A. Goštauto 12, LT-01108 Vilnius, Lithuania
}

Received 27 April 2004

\begin{abstract}
The paper presents the X-ray photoelectron spectra (XPS) of the valence band (VB) and of the principal core levels from the (110) and (001) planes for the ferroelectric semiconductor SbSI single crystal in the temperature range 215-390 K. The excitation source was $\mathrm{Al} K_{\alpha}$ monochromatic radiation (1486.6 eV). XPS were analysed in the energy range $0-1400 \mathrm{eV}$. Experimentally obtained energies were compared with the results of theoretical ab initio calculations of surface and bulk atoms in the paraelectric and ferroelectric phases. The structure of VB is calculated and confirmed experimentally. Large shifts $(3-5 \mathrm{eV})$ in the core-level binding energies of surface atoms relative to bulk atoms have been observed. They show a dramatic dependence on the surface crystallographic plane. This is the first observation of XPS shifts of that magnitude in solids. Influence of the phase transition on VB and core levels is studied and the mechanism of the XPS shifts in SbSI crystals is discussed.
\end{abstract}

Keywords: SbSI, X-ray photoelectron spectroscopy, ferroelectric

PACS: $77.84 .-\mathrm{s}, 79.60 .-\mathrm{i}$

\section{Introduction}

$\mathrm{X}$-ray photoelectron spectroscopy is widely used for surface investigations of solids. Due to the reduced coordination number, surface atoms experience a different potential than the bulk atoms. Therefore, the core-electron binding energies should be different for surface and bulk atoms. Bulk sensitive XPS enables to study the surface valence changes, which affect the core-level shift with respect to the bulk atoms.

Surface core-level shifts of the order of $\Delta E_{\mathrm{b}} \approx$ $0.5 \mathrm{eV}$ towards both higher and lower binding energies have been experimentally observed in metals [1-5], semiconductors [2,6,7], and insulators [8], as well as studied theoretically $[9,10]$. The magnitude and the sign of the shift depend on electronic and structural properties of the bulk and surface atoms, and on the surface structure [9]. For surface corelevel shifts, the initial-state potential energy as well as the final-state hole screening are important. In the materials studied the screening results only from fast electronic polarization. Therefore, one can expect large structure-dependent core-level shifts in the quasione-dimensional ferroelectric semiconductors, where the screening should be enhanced by both high ionic (phonon) and spontaneous polarization. XPS studies revealed splitting of the core levels in the incommensurate phase of the ferroelectric semiconductor $\mathrm{TIInS}_{2}[11]$.

Antimony sulphoiodide, SbSI, is the well-known quasi-one-dimensional ferroelectric semiconductor, which exhibits a number of prominent strongly coupled semiconductive and ferroelectric properties [12]. Many new phenomena in SbSI have been found [13-15], which are related to the electronic subsystem and the soft phonon mode with the frequency decreasing down to the millimetre range near $T_{\mathrm{c} 1}$, and causing high static permittivity along the [001] axis $\varepsilon \geq 30000$. Also, it has been shown [16] that SbSI has three instead of previously known two phases arising from the sequence of ferroelectric and non-ferroelectric phase transitions $P n a 2_{1} \stackrel{T_{\mathrm{c} 1}=295}{\longleftrightarrow} \mathrm{K} P 2_{1} 2_{1} 2_{1} \stackrel{T_{\mathrm{c} 2}=410}{\longleftrightarrow} \mathrm{K}$ Pnam.

Ferroelectricity in the ferroelectric semiconductors is closely related to its electronic structure [14]. The first XPS study of SbSI revealed unusual spectra in the $P 2_{1} 2_{1} 2_{1}$ phase [17]. The purpose of this paper is to study XPS in the ferroelectric semiconductor SbSI from different planes in a wide temperature range re- 
lated to the phase transition, crystal anisotropy, charging effects, screening of polarization, and illumination of the sample with light.

The organization of the paper is as follows. A brief description of the experimental details is given in Section 2. In Section 3, ab initio calculations of the photoionization energies by the Hartree-Fock-Roothan (HFR) method are presented. Section 4 presents experimental results of XPS in the ferroelectric semiconductor SbSI crystal. In Section 5, a molecular model of the SbSI crystal is described. In this section, the calculated energy levels of surface and bulk atoms in the paraelectric and ferroelectric phases are presented and compared with the experimental findings. Finally, in Section 6, the experimental and theoretical results are discussed.

\section{Experimental details}

The SbSI single crystals were grown from the vapour phase. The obtained crystals were in the form of needles or small plates of $7 \times 2 \times 1.5 \mathrm{~mm}^{3}$. The orientation of the ferroelectric [001] axis is along the needle. The XPS of the valence band and of the principal core levels were measured by PHI 5700/660 Physical Electronics Spectrometer in the temperature range $215-390 \mathrm{~K}$. The excitation source was $\mathrm{Al} K_{\alpha}$ monochromatic radiation $(1486.6 \mathrm{eV})$. The photoelectron spectra as a function of kinetic energy were analysed in the energy range $0-1400 \mathrm{eV}$ by a hemispherical mirror analyser with the energy resolution of about $0.3 \mathrm{eV}$. The measurements were performed on the (110) and (001) crystal surfaces (Fig. 1) both cleaved in vacuum, in the low $10^{-10}$ Torr range, to obtain a clean surface. The surface stoichiometry and surface quality of both (110) and (001) cleavage surfaces were checked by measuring the characteristic XPS spectrum (see, e.g., Fig. 2). The only contaminant was found to be carbon. No other spectral features showing nonstoichiometry or impurities have been found. The size of the X-ray spot was about several square microns. It did not release electrons from the (110) and (001) planes simultaneously. C $1 s$ signal at $284.5 \mathrm{eV}$ was used as the energy reference to correct for charging.

\section{3. $A b$ initio calculation of the energy levels}

The method of calculation is based on HFR equations in the LCAO MO approximation [18]. According to the Koopmans' theorem, the one-particle ener-

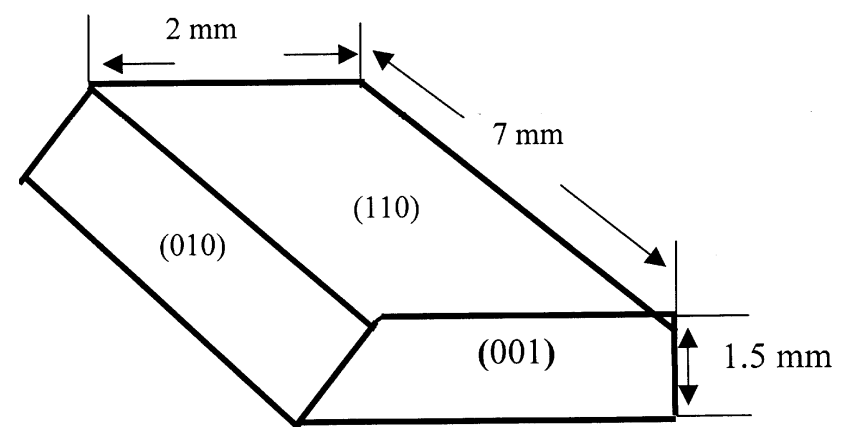

Fig. 1. Schematic view of the sample.

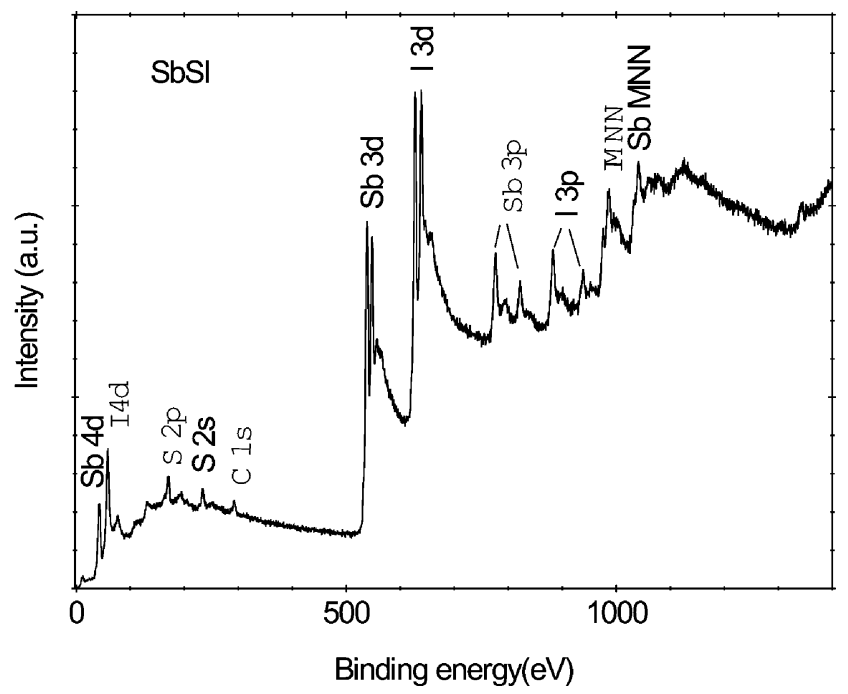

Fig. 2. XPS spectrum of SbSI in the energy range from 0 to $1400 \mathrm{eV}$.

gies obtained from the canonical RHF equations correspond to the approximate energies of the ionization potential. This would be an exact solution if the ionization process was instantaneous and the correlation energy contribution could be completely neglected. Thus, the one-particle picture of many-electron molecules in solids is far from being exact. The molecular orbital (MO) is a linear combination of atomic orbitals (AO). The MO $\varphi_{i}(\mathbf{r})$ can be expanded by the AO $\chi_{\mu}(\mathbf{r})$ base:

$$
\varphi_{i}(\mathbf{r})=\sum_{\mu=1}^{M} C_{i \mu} \chi_{\mu}(\mathbf{r}),
$$

where $\mu$ is the number of the $\mathrm{AO}$, or the set of quantum numbers $n l m$. For simplicity, a Gaussian 3G orbital basis set [19] is used. The $\mathbf{C}$ matrix is obtained by solving the Hartree-Fock matrix equation

$$
\mathbf{F C}=\mathbf{S C} \varepsilon .
$$

Equation (2) is solved by diagonalization. The solution of Eq. (2) is described in [20]. The diagonal matrix $\varepsilon$ 
gives the energies of MO levels. For the core levels they nearly correspond to the energy of the AO levels. However, due to interaction they are slightly diffused. The overlap integrals are given by

$$
S_{\mu \nu}=\int \chi_{\mu} \chi_{\nu} \mathrm{d} \mathbf{r}
$$

Fockian matrix (F) elements for molecules of closedshell singlet states can be expressed in the form

$$
F_{\mu \nu}=H_{\mu \nu}+\sum_{k, \lambda=1}^{M} P_{k \lambda}\left(\langle\mu \nu \mid k \lambda\rangle-\frac{1}{2}\langle\mu k \mid \nu \lambda\rangle\right),
$$

where

$$
H_{\mu \nu}=\int \chi_{\mu}\left(-\frac{1}{2} \Delta-\sum_{A} \frac{Z_{A}}{\left|r-r_{A}\right|}\right) \chi_{\nu} \mathrm{d} \mathbf{r}
$$

are the matrix elements of the kinetic energy of an electron and its interaction with the nucleus $Z_{A}$. The energy of the interaction between two electrons is given by

$$
\langle\mu \nu \mid k \lambda\rangle=\iint \frac{\chi_{\mu}\left(r_{1}\right) \chi_{\nu}\left(r_{1}\right) \chi_{k}\left(r_{2}\right) \chi_{\lambda}\left(r_{2}\right)}{\left|r_{1}-r_{2}\right|} \mathrm{d} r_{1} \mathrm{~d} r_{2} .
$$

The coefficients $C_{i \mu}$ allow us to calculate the electronic structure of molecules and to interpret the experimental results. They also allow us to find the matrix of the electron distribution density, according to Mulliken, which is given by

$$
P_{\mu \nu}=2 \sum_{i=1}^{N / 2} C_{i \mu} C_{i \nu}
$$

Here $N$ is the number of electrons. For the closed shells $N$ is even. As Fockian matrix $\mathbf{F}$ nonlinearly depends on unknown coefficients $C_{i \mu}$ (Eqs. (1) and (7)), Eq. (1) is solved by an iteration method.

From the orthogonalization by Löwdin density matrix

$$
\mathbf{P}=\mathbf{S}^{1 / 2} \mathbf{P S}^{1 / 2}
$$

one can find bond strengths $P_{\mathrm{AB}}$ between the atoms A and $\mathrm{B}$,

$$
P_{\mathrm{AB}}=\sum_{\mu \in \mathrm{A}} \sum_{\nu \in \mathrm{B}} P_{\mu \nu}^{2}
$$

and the charge of the atoms:

$$
q_{\mathrm{A}}=Z_{\mathrm{A}}-\sum_{\mu \in \mathrm{A}} P_{\mu \mu} .
$$

The calculations were performed with the GAMESS program [21]. We used both MINI and MIDI 3G orbital basis sets. However, for calculation of the energy levels we need a molecular model of the crystal. The model and results of calculations are discussed in Section 5. For core levels, MIDI and MINI basis set is the same. For VB, MIDI 3G basis set is contracted to the 2-1G one. MO spectrum of MIDI basis is more negative by $\sim 1 \mathrm{eV}$. The charges of atoms in MIDI basis are obtained to be $\mathrm{Sb}^{+0.82} \mathrm{~S}^{-0.50} \mathrm{I}^{-0.32}$ while in MINI basis the crystal is less polar. The dipole moment in the ferroelectric phase in MIDI basis is $2 \mathrm{D}$ while in the MINI basis it is only $1.44 \mathrm{D}$.

\section{Results of the XPS measurements}

Figure 2 shows the XPS of the SbSI crystal in the energy range from 0 to $1400 \mathrm{eV}$ below the Fermi level without contamination with any gas and only with a small amount of carbon (C $1 s$ peak at $284.5 \mathrm{eV})$. Auger spectra of Sb MNN and of I MNN are also seen in the high energy range. XPS did not show any traces of impurities, only carbon was visible after the sample was cleft under high vacuum conditions, in the low $10^{-10}$ Torr range. We did not find noticeable change of the surface composition with time at fixed temperature as well as dependence of illumination time. The strongest peaks of $\mathrm{Sb} 3 d$, I $3 d$, I $4 d$, and $\mathrm{S} 2 p$ were chosen for investigation of peculiarities of the crystallographic plane-dependent core-level XPS in this ferroelectric semiconductor.

\subsection{XPS of the valence band}

Figure 3 shows the valence band (VB) spectrum in the $P 2_{1} 2_{1} 2_{1}(330 \mathrm{~K})$ and ferroelectric $(215 \mathrm{~K})$ phases. The spectrum is referred to the Fermi level $\left(E_{\mathrm{F}}\right)$. The $E_{\mathrm{F}}$ was defined with the accuracy of $0.3 \mathrm{eV}$. In the $P 2_{1} 2_{1} 2_{1}$ phase, the VB is separated by a gap of $1.8 \mathrm{eV}$ from the Fermi level. In the ferroelectric phase, the VB is located at 2.3 to about $20 \mathrm{eV}$ below $E_{\mathrm{F}}$. The top of the VB is shifted by $\Delta E=0.53 \mathrm{eV}$ with respect to the top of the VB in the $P 2_{1} 2_{1} 2_{1}$ phase. In these crystals, the optical band gap obtained from an isoabsorption curve is $1.82 \mathrm{eV}$ at $300 \mathrm{~K}$, while the one in the ferroelectric phase is $1.89 \mathrm{eV}$ at $273 \mathrm{~K}$ and it increases at lower temperatures to $2.2 \mathrm{eV}$ [12]. It corresponds to the value obtained from the XPS measurements. The Fermi level is pinned at the bottom of the conduction band.

The jump of the spontaneous polarization $\left(P_{\mathrm{S}}\right)$ at the first-order phase transition temperature $T_{\mathrm{c} 1}$ causes the jump of $\Delta E_{\mathrm{g}}=0.075 \mathrm{eV}$. With the decrease of temperature $P_{\mathrm{S}}$ increases to about $20 \cdot 10^{-6} \mathrm{C} / \mathrm{cm}^{2}$ and causes 


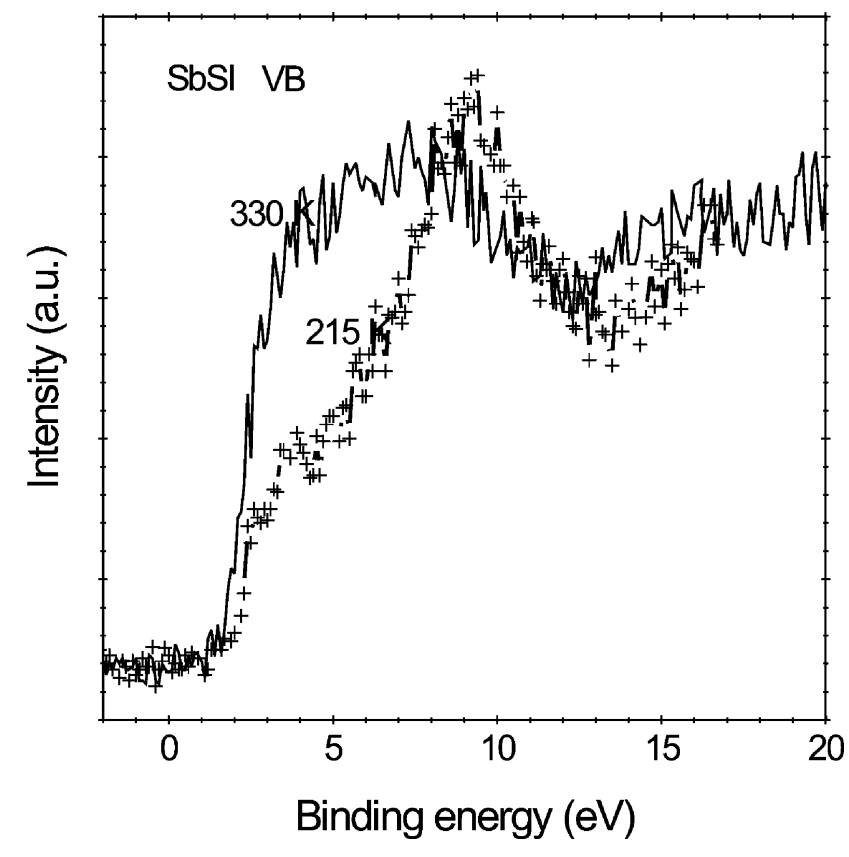

Fig. 3. XPS of the valence band in the $P 2_{1} 2_{1} 2_{1}(330 \mathrm{~K})$ and ferroelectric $(215 \mathrm{~K})$ phases.

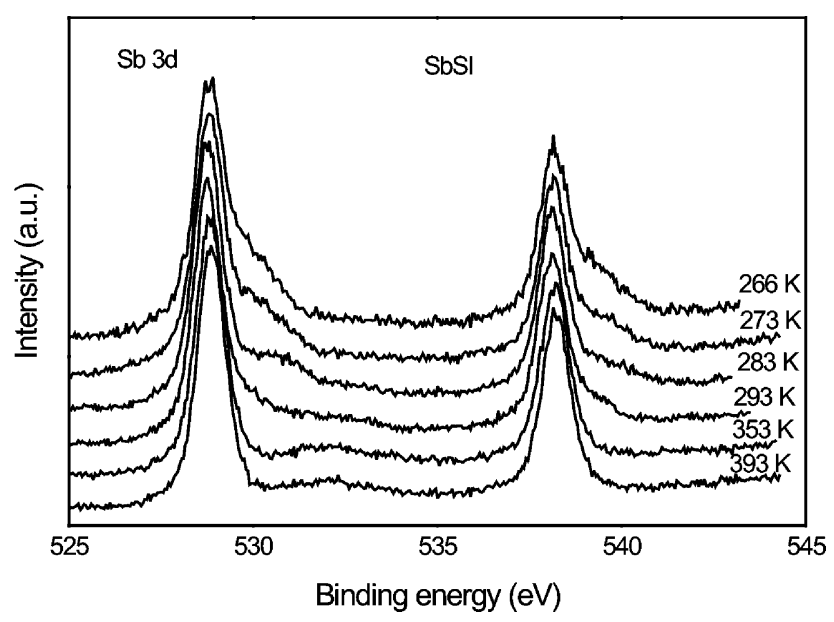

Fig. 4. XPS of the Sb $3 d$ spin-orbit doublet from the (110) plane at different temperatures.

increase of $E_{\mathrm{g}}(T)$. As a result, the top of the valence band shifts with respect to the Fermi level. The change of the shape of VB in the ferroelectric phase will be discussed in Section 6. In the paraelectric phase, the shape of VB does not depend on temperature.

\subsection{XPS of core levels from the (110) plane}

The (110) plane is parallel to the ferroelectric axis (see Section 5). Figure 4 shows the spectrum of the spin-orbit doublet of $\mathrm{Sb} 3 d$ at different temperatures. The core-level binding energy is referred (in all fig-
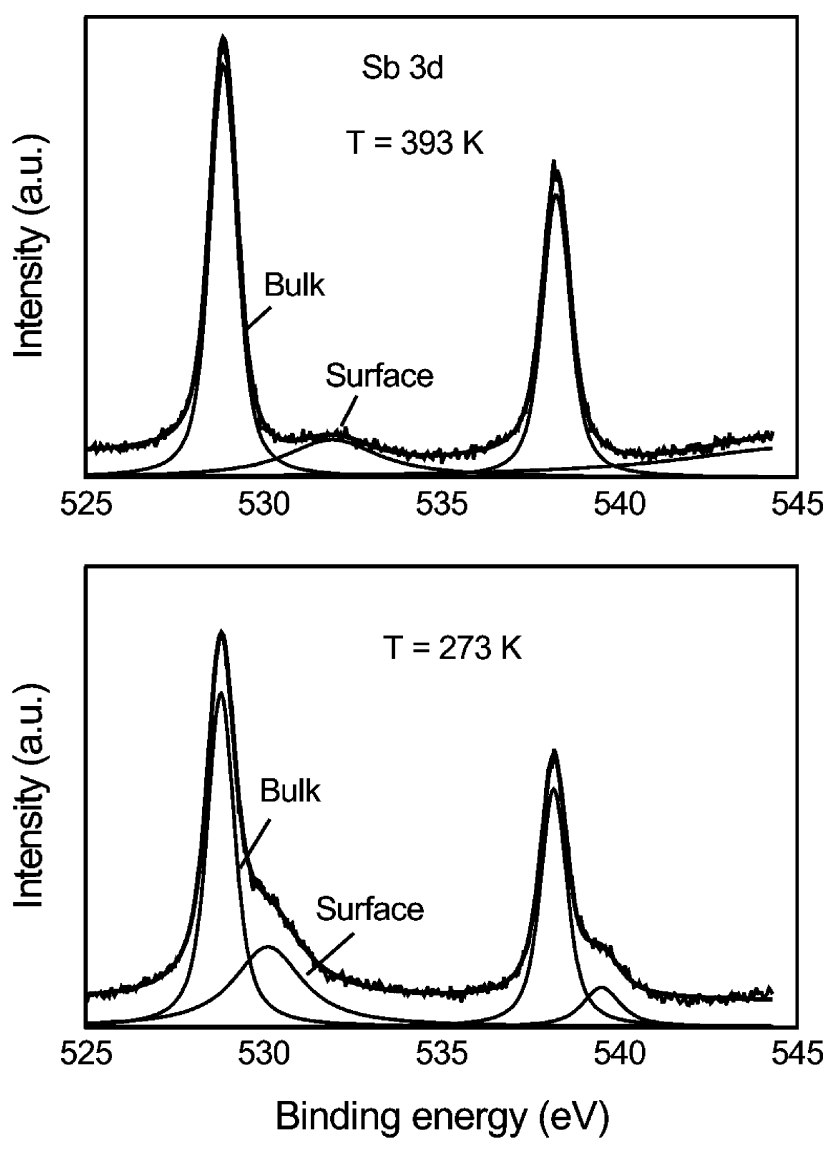

Fig. 5. Gaussian XPS contributions of the Sb $3 d$ spin-orbit doublet from the (110) plane.

ures) to the Fermi level with the calibration accuracy of $\pm 0.3 \mathrm{eV}$. The peaks of $\mathrm{Sb} 3 d_{5 / 2}$ and $3 d_{3 / 2}$ are situated at about 529 and $538 \mathrm{eV}$, respectively. Referencing to $E_{\mathrm{F}}$ for ferroelectric semiconductor requires understanding the magnitude of the polarization effects [8] for the reference to be accurate. We pinned these values at all temperatures by calibrating the spectra with the $\mathrm{C} 1 s$ peak. The state of this carbon is not clear and the binding energy of the $\mathrm{C} 1 s$ signal might be slightly changed. However, the experiments confirmed that this change was very small. The binding energy, $E_{\mathrm{b}}$, in SbSI increases by about $1 \mathrm{eV}$ in comparison with $E_{\mathrm{b}}$ in pure $\mathrm{Sb}\left(E_{\mathrm{b}}=528 \mathrm{eV}\right.$ for $3 d_{5 / 2}$ and $E_{\mathrm{b}}=528 \mathrm{eV}$ for $3 d_{3 / 2}$ ). The background is caused by secondary electrons. However, the spectrum is temperature-dependent: every line of the spin-orbit doublet is split into two components, which are clearly seen in Fig. 5 after resolving the spectrum into Gaussian contributions. The split components are separated by about $3 \mathrm{eV}$ at $393 \mathrm{~K}$ and by $1.2 \mathrm{eV}$ at $273 \mathrm{~K}$.

The position, pinned by calibration, of I $3 d_{5 / 2}$ is at $E_{\mathrm{b}}=618.2 \mathrm{eV}$ and of $\mathrm{I} 3 d_{3 / 2}$ at $E_{\mathrm{b}}=629.2 \mathrm{eV}$. The chemical shift is about $0.8 \mathrm{eV}$ to lower values (for 


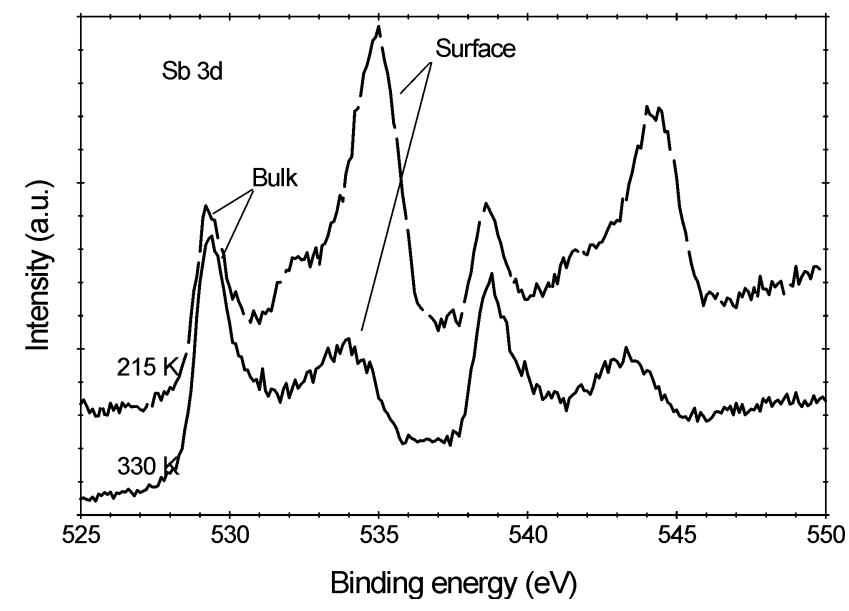

Fig. 6. XPS of the Sb $3 d$ spin-orbit doublet from the (001) plane.

pure I $3 d_{5 / 2}$ it is at $E_{\mathrm{b}}=619 \mathrm{eV}$ and for I $3 d_{3 / 2}$ at $\left.E_{\mathrm{b}}=630\right)$.

The position of the overlapping $\mathrm{S} 2 p_{3 / 2}$ and $\mathrm{S} 2 p_{1 / 2}$ peaks were obtained at about 161 and $162 \mathrm{eV}$. In the isostructural semiconductor $\mathrm{Sb}_{2} \mathrm{~S}_{3}$ these values are at about 161.5 and $162 \mathrm{eV}$, respectively [22]. For sulphur, the chemical shift is in the opposite direction in relation to $\mathrm{Sb}$, i. e. to lower binding energy about $3 \mathrm{eV}$ (for pure $\mathrm{S} 2 p_{3 / 2} E_{\mathrm{b}}=164 \mathrm{eV}$ and for $\left.2 p_{1 / 2} E_{\mathrm{b}}=165 \mathrm{eV}\right)$.

The shift of the binding energy with temperature indicates changes of the chemical environment of the $\mathrm{Sb}$, $\mathrm{I}$, and $\mathrm{S}$ atoms and redistribution of the atomic charge due to the chemical bonding.

Thus, the electronic structure measurements revealed the chemical shift of $\mathrm{Sb}$ states of $+1 \mathrm{eV}$ to higher binding energy, and I states of $-0.8 \mathrm{eV}$ and $\mathrm{S}$ states of $-3 \mathrm{eV}$ to lower binding energy. This shift suggests charge transfer from $\mathrm{Sb}$ to $\mathrm{S}$ and $\mathrm{I}-$ more to $\mathrm{S}$ than to I.

\subsection{Surface effects on the (001) plane core-level binding energies}

The most striking results of the XPS in this quasione-dimensional ferroelectric semiconductor were obtained from the (001) plane, which is perpendicular to the spontaneous polarization axis. Figure 6 shows the photoelectron emission spectrum of the spin-orbit doublet of $\mathrm{Sb} 3 d_{5 / 2}$ and $3 d_{3 / 2}$ in different phases. The huge temperature-dependent split of each component of the spin-orbit doublet is obtained. At $330 \mathrm{~K}$, this split is about $4 \mathrm{eV}$. In the ferroelectric phase $(215 \mathrm{~K})$ the split is about $5 \mathrm{eV}$. Similar split was obtained for the spin-orbit doublets of I $3 d_{5 / 2}$ and $3 d_{3 / 2}$, and I $4 d_{5 / 2}$ and $4 d_{3 / 2}$. Figure 7 shows this split. S $2 p$ spin-orbit doublet components are also split. It is tempting to assign the dif-

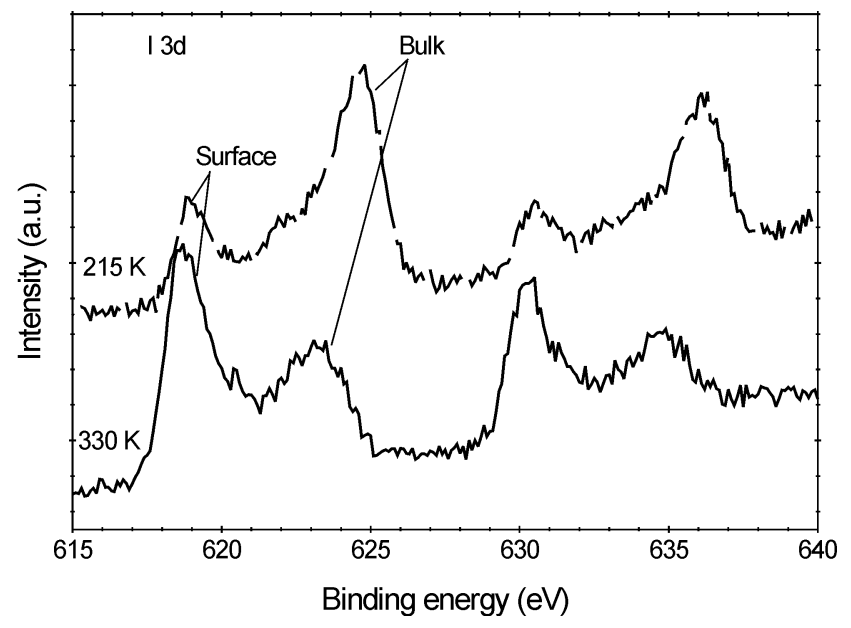

(a)

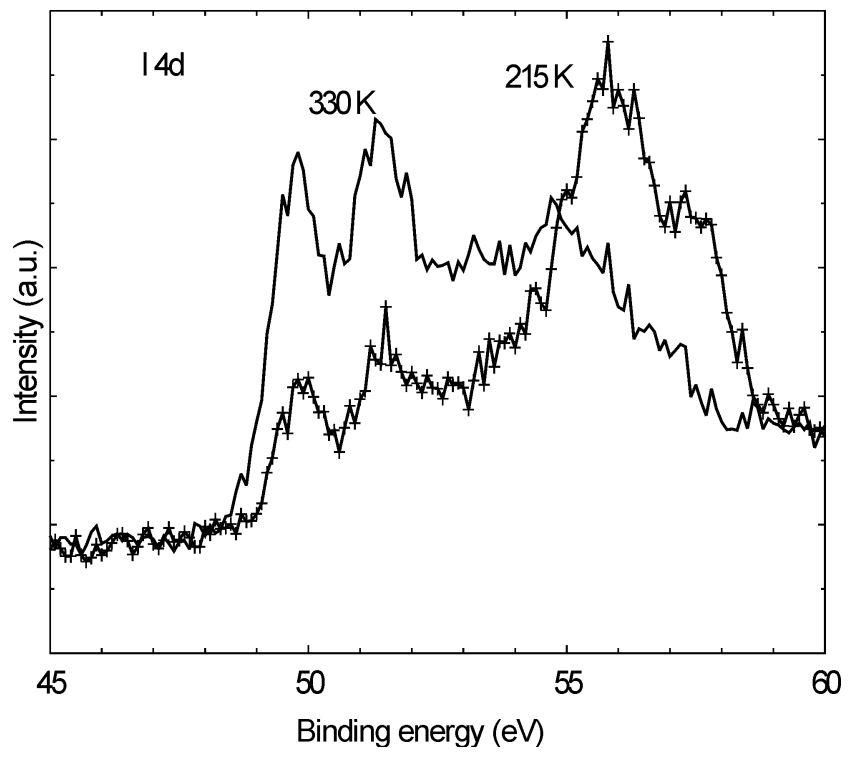

(b)

Fig. 7. XPS of the I $3 d$ and I $4 d$ spin-orbit doublets from the (001) plane. Two left peaks are referred to the $d_{5 / 2}$ while two right peaks belong to the $d_{3 / 2}$. The negative binding energy of the surface atoms is lower than of the bulk atoms (see Table 1).

ferent components of the split spin-orbit doublets to the surface and bulk contributions. After the sample breaking in perpendicular to the [001] axis, a sample tends to split into thin needles. Due to the cleaving of the crystal the surface-to-bulk ratio increases. The intensity ratio between the bulk and the surface also changes dramatically (Figs. 5 and 6). It reflects modification of sample geometry but not sample composition.

Due to the reasons mentioned in the introduction the core-electron binding energies should be different for surface and bulk atoms. Such a shift was observed in metals, semiconductors, and insulators. However, the magnitude of the shift in the quasi-one-dimensional 


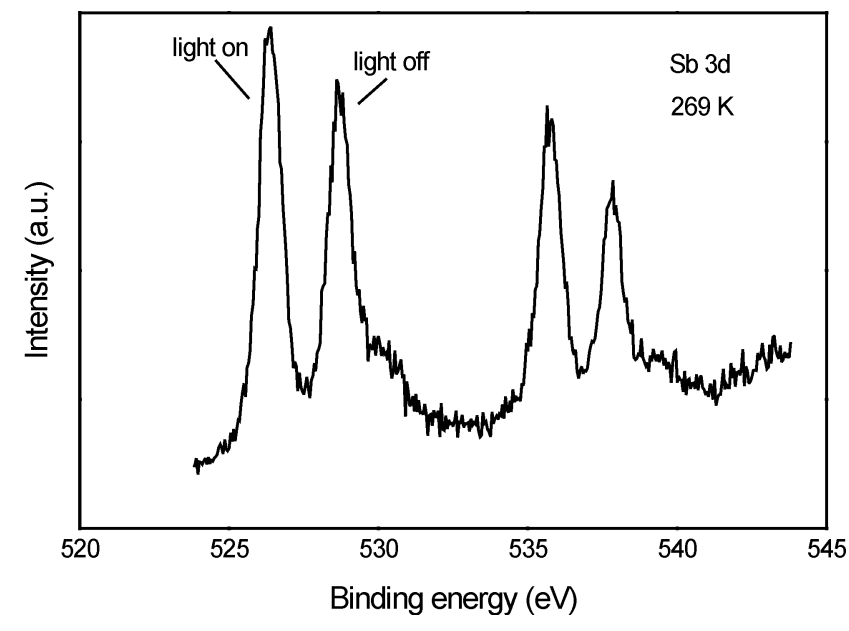

Fig. 8. Influence of light on the XPS of the spin-orbit doublet of the $\mathrm{Sb} 3 d_{5 / 2}$ (left lines) and $3 d_{3 / 2}$ (right lines) from the (001) plane. Only the shift of the lines is shown. The first and third lines correspond to an illuminated crystal.

SbSI crystal is found to be particularly large for (001) surface. It reflects the large change in electron density at the atoms that emit the photoelectrons. Thus, one may assume that XPS in SbSI are bulk and crystallographic plane dependent. The split components of the XPS were assigned to the crystal surface and bulk on the basis of theoretical calculations (see Table 1).

\subsection{Influence of light}

SbSI is highly photosensitive material [12]. Illumination of the crystal with a visible light shifts the corelevel spectra. Figure 8 shows the strong shift of the spin-orbit doublet of $\mathrm{Sb} 3 d_{5 / 2}$ and $3 d_{3 / 2}$ from the (110) plane in the ferroelectric phase. The composition of two different spectra taken under different illumination is shown. When the crystal is illuminated with visible light the $\mathrm{Sb} 3 d_{5 / 2}$ and $3 d_{3 / 2}$ lines shift about $2.5 \mathrm{eV}$ to lower binding energies. We will discuss the origin of this shift in Section 6.

\section{The model of SbSI structure and calculated Koopmans' energies}

For the theoretical $a b$ initio calculation of energy levels the molecular model of the SbSI crystal is needed. The model must be a cluster composed from an even number of molecules. The interaction between the clusters is assumed to be weak.

A projection of the crystal structure of SbSI on the (001) plane is shown in Fig. 9(a). It contains double chains $\left[(\mathrm{SbSI})_{\infty}\right]_{2}$ consisting of two chains related by a twofold screw axis and linked together by a short and strong Sb-S bonds [16]. In the ferroelectric $P n a 2_{1}$ and the antiferroelectric $P 2_{1} 2_{1} 2_{1}$ phases the double chains are polar due to alternating shorter and longer $\mathrm{Sb}-\mathrm{S}$ as well as Sb-I bonds (Figs. 9(c) and (d)). The asymmetry of the $(\mathrm{S}, \mathrm{I})$ arrangement results in polarity of the double chains which in the ferroelectric phase are all oriented in the same direction. In the $P 2_{1} 2_{1} 2_{1}$ phase the arrangement of the polar double chains becomes antiparallel (up and down). Weak van der Waals-type bonds of $d>3.8 \mathrm{eV}$ bind the double chains. The transport of electrons and holes along the [001] axis suggests the large anisotropy in the mobility of the carriers, and in the electrical conductivity. Along the [001] axis the conductivity is of the order of $10^{-6} \mathrm{~S} / \mathrm{m}$, while in perpendicular directions it is of the order of $10^{-8} \mathrm{~S} / \mathrm{m}$. For such conductivity the charging effects are important [8]. The weakly bonded double chains may be considered as non-interacting and one double chain may be taken as a molecular model of the crystal for the binding energies calculation.

The double chain is formed of many simplified unit cells. One such simplified unit cell consists of six atoms. Four and two such unit cells, as a molecular model of SbSI crystal, have been considered for the energy levels calculations. It was found that when $\mathrm{Sb}$ atoms are at a distance $d>4.01 \AA$ they can be considered as non-interacting. When they approach $2.81 \AA$, the chemical bonds appear, the energy levels split and shift by $1 \mathrm{eV}$ to higher energies. When the SbSI molecule is formed, the energy levels split into two groups separated by $1.4-1.5 \mathrm{eV}$ gap. Energy levels slightly change with the increase of the cluster. It means that the model of only two SbSI molecules (middle part of Fig. 9(a)) is sufficient to describe qualitatively the electronic spectrum of the crystal. It was found that the quantum-chemical calculations are very sensitive to small variation of the surface geometry. Small perturbation of the surface (open or H-terminated bonds) changes the core-level binding energy.

After breaking the crystal under high vacuum conditions some bonds of surface atoms become open. Due to the reduced coordination number, surface atoms experience different potential than the bulk atoms. We have calculated by the HFR method the energy of the VB and core levels for: (i) surface atoms open bonds, and (ii) the hydrogen-terminated bonds. In the case (i), the binding energies correspond to surface atoms, while in the case (ii) they correspond to a bulk-like spec- 


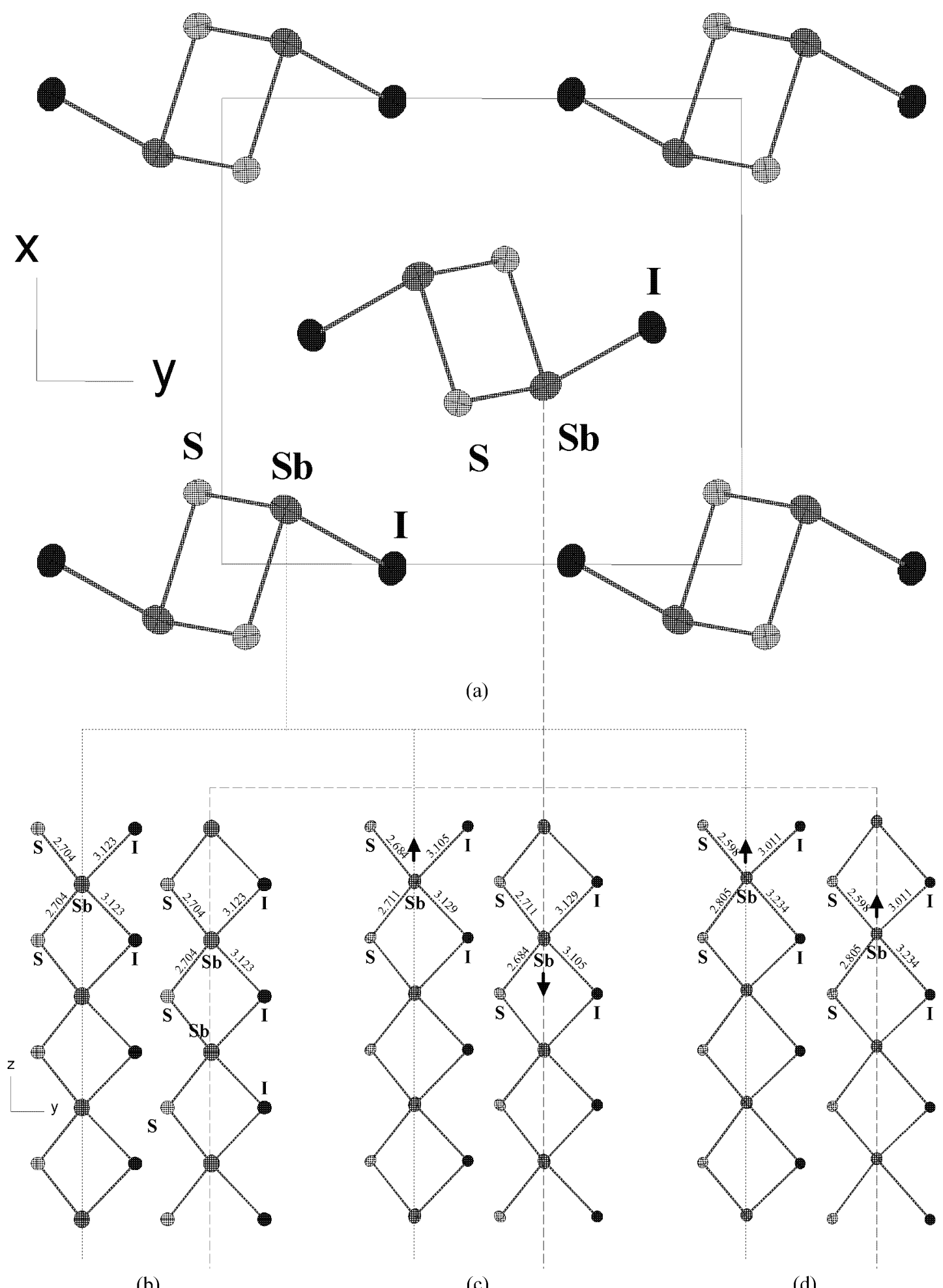

(b)

(c)

(d)

Fig. 9. (a) Crystal structure of SbSI in projection on the (001) plane. Double chains and interatomic distances at (b) $465 \mathrm{~K}$, (c) $315 \mathrm{~K}$, and (d) $287 \mathrm{~K}$ along the [001]-axis. Strong Sb-S bonds connecting the single chains are not shown.

trum. Any screening effects in the simplified molecular model of the SbSI crystal were not taken into account.

Table 1 presents the mean theoretical values of the binding energies of bulk and surface atoms in the paraelectric and ferroelectric phases, calculated with MINI basis set without taking into account the spinorbit interaction, and experimentally obtained energies $E_{\mathrm{b}(\exp )}$. The shift in the core level binding energy 
Table 1. Mean theoretical values of binding energies (negative) in bulk, $E_{\mathrm{b}(\mathrm{bulk})}$, and surface, $E_{\mathrm{b} \text { (surface) }}$, states in two phases, and the experimental values at $300 \mathrm{~K}$ (in eV). Limits $( \pm)$ show the interval of states.

\begin{tabular}{|c|c|c|c|c|c|}
\hline \multirow[t]{2}{*}{ State } & \multicolumn{2}{|c|}{ Paraelectric phase } & \multicolumn{2}{|c|}{ Ferroelectric phase } & \multirow{2}{*}{$E_{\mathrm{b}(\exp )}$} \\
\hline & $E_{\mathrm{b}(\mathrm{bulk})}$ & $E_{\mathrm{b}(\text { surface })}$ & $E_{\mathrm{b}(\mathrm{bulk})}$ & $E_{\mathrm{b}(\text { surface })}$ & \\
\hline I $3 s$ & 1026.5 & 1023.9 & 1026.6 & 1023.9 & \\
\hline $\mathrm{Sb} 3 s$ & 910.2 & 912.7 & 910.4 & 912.6 & \\
\hline I $3 p$ & $895.6 \pm 0.1$ & $892.9 \pm 0.1$ & $895.7 \pm 0.1$ & $893.1 \pm 0.2$ & 890-900 \\
\hline $\mathrm{Sb} 3 p$ & $786.9 \pm 0.1$ & 790.4 & $786.6 \pm 0.2$ & $789.2 \pm 0.3$ & $785-800$ \\
\hline I $3 d$ & $653.1 \pm 0.1$ & $650.4 \pm 0.1$ & $653.2 \pm 0.1$ & $650.5 \pm 0.3$ & $618.5-630$ \\
\hline $\mathrm{Sb} 3 d$ & $558.7 \pm 0.1$ & 561.3 & $558.9 \pm 0.7$ & $561.2 \pm 0.1$ & $529-538.5$ \\
\hline $\mathrm{S} 2 s$ & $241.2 \pm 0.4$ & $239.1 \pm 0.3$ & $241.3 \pm 0.6$ & $239.1 \pm 0.1$ & $\sim 230$ \\
\hline I $4 s$ & 194.6 & 191.7 & 194.7 & $191.7 \pm 0.3$ & \\
\hline S $2 p$ & $177.1 \pm 0.1$ & 175.0 & $177.1 \pm 0.7$ & $175.0 \pm 0.2$ & $161-162$ \\
\hline $\mathrm{Sb} 4 s$ & 163.0 & 164.8 & 163.0 & $164.8 \pm 0.1$ & \\
\hline I $4 p$ & $146.1 \pm 0.1$ & $143.6 \pm 0.2$ & $146.9 \pm 0.7$ & $143.7 \pm 0.4$ & \\
\hline $\mathrm{Sb} 4 p$ & $119.1 \pm 0.5$ & 120.8 & $119.1 \pm 1.1$ & $120.8 \pm 0.1$ & \\
\hline I $4 d$ & $62.7 \pm 0.4$ & $60.0 \pm 0.2$ & $63.5 \pm 1.2$ & $60.0 \pm 0.5$ & $50-56$ \\
\hline $\mathrm{Sb} 4 d$ & $44.6 \pm 1.0$ & $45.8 \pm 0.1$ & $44.5 \pm 1.6$ & $45.8 \pm 0.2$ & $35-40$ \\
\hline VB (s-band) & $18.8-27.3$ & $14.4-23.7$ & $18.2-27.5$ & $14.4-23.8$ & $13-23$ \\
\hline VB ( $p$-band) & $2.4-14.0$ & $5.9-9.6$ & $2.5-14.3$ & $5.9-9.6$ & $1.8-12$ \\
\hline
\end{tabular}

of surface $\mathrm{Sb}$ atoms relative to bulk atoms is positive (the negative energy increases), while for I and $\mathrm{S}$ atoms is negative (energy decreases) and is large enough even in this approximation. Such a shift of even larger magnitude was observed experimentally.

The energies of core levels were calculated also by the Hartree-Fock-Dirac method. It takes into account experimentally obtained spin-orbit splitting of the XPS. However, the both quantum-mechanical methods give higher negative core-level energies than are their experimental values.

\section{Discussion}

Theoretical HFR calculations give the ionization potential with its zero at the vacuum level of the sample. It exceeds a binding energy referred to the Fermi level by a work function. From the theoretical calculations the bulk work function of SbSI is obtained to be $3.2 \mathrm{eV}$ while the surface one is $6.8 \mathrm{eV}$. Theoretical calculations qualitatively explain the experimental values of XPS. Nevertheless, the theoretical eigenvalues of the valence band and core levels are higher than the experimental binding energies (Table 1). Some discrepancy is because: (i) a limited basis set of $120 \mathrm{AO}$ for obtaining a molecular orbital solution is used (in the case of two SbSI molecules as the crystal model); (ii) screening effects are not taken into account. But the main source of discrepancy is (iii) the used Gaussian orbital basis set [19] being not accurate enough. Nevertheless,
Koopmans' theorem provides an invaluable tool in assigning XPS.

From the theoretical calculations of the electronic spectrum presented in Table 1 it follows that the phase transition at $T_{\mathrm{c} 1}$ shifts the core levels by less than $\Delta E_{\mathrm{b}} \approx 0.2 \mathrm{eV}$. In the ferroelectric phase XPS broaden. The top of the valence band in the ferroelectric phase increases only by $0.1 \mathrm{eV}$. Experimentally obtained shift (Fig. 3) is caused by the increase of the band gap with the decrease of temperature.

Calculations of the $C_{i \mu}$ coefficients (Eq. (1)) show that VB consists of $s$ - and $p$-bands separated by $4-5 \mathrm{eV}$. $\mathrm{Sb} 5 s, \mathrm{~S} 3 s, \mathrm{I} 5 s$, and $\mathrm{S} 2 s$ states give the main contribution to the $s$-band, while $p$-band mainly consists of $\mathrm{Sb} 5 p$ and $\mathrm{S} 3 p$ states. Sb $4 p$ and I $4 p$ states also give some contribution. $\mathrm{Sb} 5 p$ state forms the top while $\mathrm{S} 3 p$ forms the high-energy edge of the $p$-band. $\mathrm{Sb} 5 s$ state forms low-energy edge while $\mathrm{S} 3 s$ the highenergy edge of the $s$-band. I $5 s$ state causes the middle of $s$ - and $p$-bands. The AO of surface atoms are more localized while AO of bulk are delocalized. Due to reasons mentioned above the theoretical VB from $2.4 \mathrm{eV}$ extends to $27.2 \mathrm{eV}$. The bulk $p$-band lies from 2.4 to $14 \mathrm{eV}$ and $s$-band lies from 18.8 to $27.2 \mathrm{eV}$. Experimentally we also have found $s$ - and $p$-bands (Fig. 3). The surface $p$-band contracts from 12 to about $4 \mathrm{eV}$.

The experimentally observed large core-level energies splitting results are fairly well repeatable. The additional excitations of the spin-orbit doublet of $\mathrm{Sb} 3 d$, which move to lower energies with the decrease of tem- 
Table 2. Bond orders (density of electrons between the atoms) and Mulliken charges of bulk and surface atoms in $P 2_{1} 2_{1} 2_{1}$ and ferroelectric phases.

\begin{tabular}{|c|c|c|c|c|}
\hline \multirow[t]{2}{*}{ Bond } & \multicolumn{2}{|c|}{ Bulk } & \multicolumn{2}{|c|}{ Surface } \\
\hline & Para & Ferro & Para & Ferro \\
\hline \multicolumn{5}{|c|}{ Bond orders } \\
\hline \multirow[t]{4}{*}{$\mathrm{Sb}-\mathrm{S}$} & 0.85 & 0.68 & 0.93 & 0.93 \\
\hline & 0.28 & 0.12 & 0.86 & 0.88 \\
\hline & 0.86 & 0.95 & 0.93 & 0.93 \\
\hline & 0.28 & 0.48 & 0.86 & 0.85 \\
\hline \multirow[t]{2}{*}{$\mathrm{Sb}-\mathrm{I}$} & 0.06 & 0.05 & 0.82 & 0.83 \\
\hline & 0.06 & 0.07 & 0.82 & 0.82 \\
\hline \multicolumn{5}{|c|}{ Mulliken charges } \\
\hline & $\mathrm{Sb}^{+0.21}$ & $\mathrm{Sb}^{+0.05}$ & $\mathrm{Sb}^{+0.82}$ & $\mathrm{Sb}^{+0.81}$ \\
\hline & $\mathrm{S}^{-0.51}$ & $\mathrm{~S}^{-0.51}$ & $\mathrm{~S}^{-0.50}$ & $\mathrm{~S}^{-0.52}$ \\
\hline & $\mathrm{I}^{+0.08}$ & $\mathrm{I}^{+0.04}$ & $\mathrm{I}^{-0.32}$ & $\mathrm{I}^{-0.33}$ \\
\hline & $\mathrm{Sb}^{+0.21}$ & $\mathrm{Sb}^{+0.37}$ & $\mathrm{Sb}^{+0.82}$ & $\mathrm{Sb}^{+0.81}$ \\
\hline & $\mathrm{S}^{-0.51}$ & $\mathrm{~S}^{-0.53}$ & $S^{-0.50}$ & $S^{-0.46}$ \\
\hline & $\mathrm{I}^{+0.08}$ & $\mathrm{I}^{+0.14}$ & $\mathrm{I}^{-0.32}$ & $\mathrm{I}^{-0.49}$ \\
\hline
\end{tabular}

perature (Figs. 4 and 5), may be related to the influence of surface. Theoretical calculations support this idea (Table 1).

However, one can find another reason of these excitations. We used the Hartree-Fock method including relativistic effects to calculate intensity of the $\mathrm{Sb} 3 d$ lines by ionizing the $\mathrm{Sb}$ ion from the main level of the $5 s 5 p^{3}, 5 s^{2} 5 p^{2}$, and $5 s^{2} 5 p^{5} d$ configurations, and by knocking out an electron from the $3 d$ level. The intensity of lines is given by

$$
\begin{aligned}
& I\left(K \gamma_{p} J_{p} \Rightarrow K 3 d^{-1} \gamma L S J S\right) \\
& \quad \sim N\left(K \gamma_{p} J_{p}\right) \sigma\left(K \gamma_{p} J_{p} \Rightarrow K 3 d^{-1} \gamma L S J S\right),
\end{aligned}
$$

where $K$ is the configuration, $\gamma_{p} J_{p}$ is the angular momentum $\left(J_{p}\right)$ of the main level, and other multielectron quantum numbers $\left(\gamma_{p}\right), N\left(K \gamma_{p} J_{p}\right)$ is the occupancy of the main level considering that $N\left(K \gamma_{p} J_{p}\right) \sim 2 J_{p}+1$, and $\sigma$ is the cross-section of the photoionization. The calculations have shown that photoionization of the $\mathrm{Sb}$ ion from the configuration $5 s^{2} 5 p^{5} d$ shifts the $3 d$ binding energies to higher values, and excites additional lines. Also, due to before-collapse state of the exited $5 d$ electron's wave function, it is very sensitive to the change of the local field.

In order to understand the large shift of the core-level binding energies from the (001) plane several reasons were analysed. First, a domain boundary may cause appearance of inequivalent positions of atoms. However, the calculations of the core-level binding energies have shown that the ferroelectric domain boundaries may shift the binding energies less than $0.5 \mathrm{eV}$. Thus,

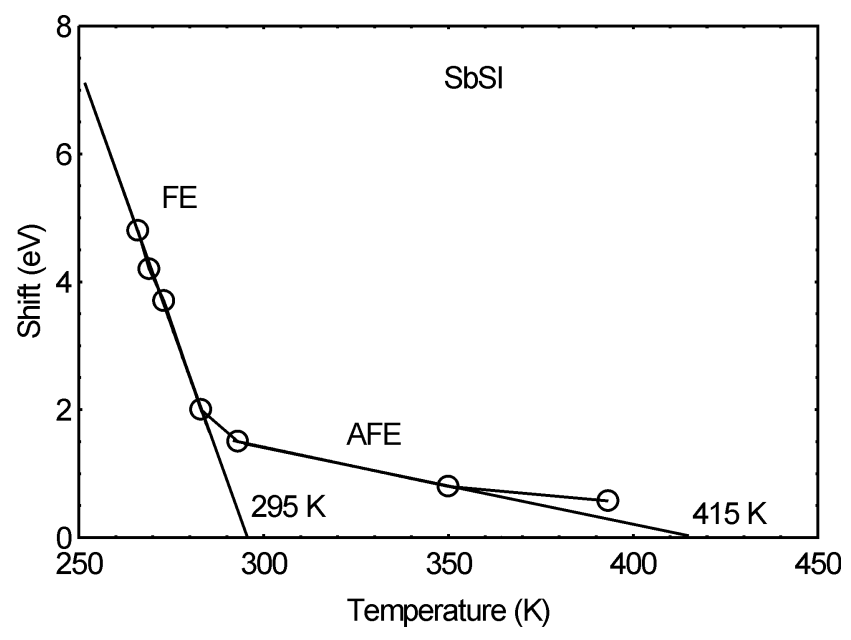

Fig. 10. Shift of the Fermi level and XPS on temperature. All the core-level binding energies were shifted by the same value.

the domain structure cannot explain experimentally observed large shift of the core-level energies.

Second, it is known that the binding energy shifts of surface atoms relative to bulk atoms from different planes may differ in magnitude several times [9]. Breaking of the strong bonds in (001) plane (Fig. 9) may cause large shifts of the binding energies from the (001) surface. Table 1 also shows that the shift of binding energy of surface atoms is about $2.6-2.7 \mathrm{eV}$ for $\mathrm{Sb} 3 d$ and I $3 d$ and about $2.1 \mathrm{eV}$ for S $2 p$. Similar shifts are for all levels. Bond orders and Mulliken charges of surface atoms also differ considerably from bulk atoms (Table 2). Bonds become stronger on the surface. Surface atoms are also less sensitive to the phase transition. The dipole moment of the surface is $2 \mathrm{D}$ while of the bulk it is $3.79 \mathrm{D}$. The charge of surface $\mathrm{Sb}$ and I atoms is much higher than of bulk-like atoms. Such changes should give different XPS of the bulk and the surface. So, the results presented in Figs. 6 and 7 may be interpreted as the huge crystallographic plane-dependent core-level binding energy shifts of surface atoms relative to bulk atoms.

Third, in ferroelectric semiconductor screening of polarization and charging effects are also important. All properties of the surface differ from the bulk properties [23]. High concentration of electrons or holes is needed for the screening of high ionic and spontaneous polarization. This causes high band binding (which approaches to the magnitude of the bandgap), a field effect and surface layers of $n$ - and $p$-conductivity.

By solving the Poisson equation the surface charge density, thickness of the surface layer, and the surface electric field was estimated. 
The surface charge density is

$$
N_{0}=\frac{P_{\mathrm{s}}^{2}}{2 \varepsilon_{0} \varepsilon k T}
$$

and the surface layer thickness is

$$
z_{0}=\frac{P_{\mathrm{s}}}{e N_{0}} .
$$

Both values, $N_{0}$ and $z_{0}$, are temperature dependent. For SbSI at $T=300 \mathrm{~K}, P_{\mathrm{s}} \approx 0.1 \mu \mathrm{C} / \mathrm{cm}^{2}, \varepsilon=$ $(15-20) \cdot 10^{3}$ [13]. From Eqs. (11) and (12) we obtain $N_{0} \approx 10^{16} \mathrm{~cm}^{-3}$ and $z_{0} \approx(1-2) \cdot 10^{-4} \mathrm{~cm}$. Surface layers of similar thickness are known for $\mathrm{BaTiO}_{3}$ and other ferroelectrics [23]. However, for the temperature $250 \mathrm{~K}$, where $P_{\mathrm{s}} \approx 20 \mu \mathrm{C} / \mathrm{cm}^{2}$ and $\varepsilon \approx 400$, we obtain $N_{0}=10^{21} \mathrm{~cm}^{-3}$ and the surface layer is only $z_{0} \approx 4 \AA$. The surface electric field, caused by free charge carriers compensating the spontaneous polarization, exceeds many kilovolts per centimetre. It increases on cooling the crystal. This surface field shifts the Fermi level and the core-level XPS to higher binding energies. This shift was measured using the carbon $\mathrm{C} 1 s$ peak and the position of all the spectra (Figs. 2-8) was corrected. Figure 10 shows this shift. Although the XPS were measured and calibration made at many temperatures, only some points are shown in Fig. 10. The two lines show the phase transition temperatures, $T_{\mathrm{c} 1}$ and $T_{\mathrm{c} 2}$. The appearance of a small polarity in the $P 2_{1} 2_{1} 2_{1}$ phase $(295 \mathrm{~K}<T<415 \mathrm{~K})$ charges the crystal surface and the produced surface electric field shifts the core-level XPS. In the ferroelectric phase ( $T<295 \mathrm{~K}$ ), in addition to charging due to the increased bandgap and decreased conductivity the sharp shift of the XPS on cooling is influenced by the strong increase of the spontaneous polarization. Nevertheless, the calibration with the $\mathrm{C} 1 \mathrm{~s}$ peak allowed measuring nearly a proper position of the core-level XPS.

From the Poisson equation one can obtain the surface potential

$$
V_{\mathrm{s}} \approx Q_{+} \frac{h}{\varepsilon},
$$

where $h$ is the thickness of the crystal and $Q_{+}$is the positive charge density. A positive surface potential $V_{\mathrm{s}}$ is equivalent to the increase of the electron energy affinity which leads to the increase of the normal component of the momentum of the electrons that may escape into vacuum. Any local change of the permittivity, $\varepsilon$, or $h$ will induce the lateral change of $V_{\mathrm{s}}$ and then of the electron emission intensity. The change of charging due to change of the spontaneous polarization may change the direction of the internal electric field, and this field may push the slow photoelectrons emitted from the crystal to go back towards it. A separate task is a calculation of the intensity of emission in the presence of the strong electric field in the $z_{0}$ layer in a ferroelectric semiconductor of such electric conductivity.

Illumination of the crystal with visible light induces a decrease of the temperature-dependent surface potential $V_{\mathrm{S}}$ and of the internal electric field, and thus corelevel XPS shift. As a result, XPS peaks appear at lower binding energy (Fig. 8).

Finally, no such splitting of core-level energy was observed in $\mathrm{Sb}_{2} \mathrm{~S}_{3}$ or $\mathrm{Bi}_{2} \mathrm{~S}_{3}$ crystals [22,24]. It seems that the large splitting of core-level energy is characteristic of highly anisotropic quasi-one-dimensional crystals.

\section{Conclusions}

$\mathrm{X}$-ray photoelectron spectra of the valence band and of the principal core levels of the semiconductor ferroelectric SbSI crystal are presented in the energy range from 0 to $1400 \mathrm{eV}$ at different temperatures. A molecular model of the crystal is used for $a b$ initio theoretical calculations of the binding energies. Theoretical values of the binding energies are close to the experimental ones. The structure of valence band is calculated and confirmed experimentally. The XPS studies revealed the huge crystallographic planedependent shifts $(\sim 3-5 \mathrm{eV})$ of surface atoms relative to bulk atoms. Theoretical ab initio calculations confirmed these findings. XPS are sensitive to surface potential changes but these changes take their origin in the bulk of the crystals. The presence and temperature dependence of the spontaneous polarization charges a surface of the crystal and shifts the spectrum. Changes of the Fermi energy and bandgap at the phase transition also shift the spectrum. Therefore, the valence band and core levels of this quasi-one-dimensional semiconductor ferroelectric are extremely sensitive to changes of the chemical environment of atoms, phase transition, and spontaneous polarization.

\section{References}

[1] J.F. Van der Veen, F.J. Himpsel, and D.E. Eastman, Structure-dependent $4 f$-core-level binding energies for surface atoms on $\operatorname{Ir}(111), \operatorname{Ir}(100)$ and metastable $\operatorname{Ir}(100)$, Phys. Rev. Lett. 44, 189 (1980).

[2] G. Kaindl, C. Laubschat, B. Reihl, R.A. Pollak, N. Märtensson, F. Holtzberg, and D.E. Eastman, Sur- 
face effects on core-level binding energies and valence in thulium chalcogenides, Phys. Rev. B 26, 1713 (1982).

[3] H.-J. Brocksch, D. Tomanek, and K.H. Bennemann, Calculation of surface core-level shifts in intermediatevalence compounds, Phys. Rev. B 27, 7313 (1983).

[4] A.J. Maxwell, P.A. Brühweilller, A. Nelson, and N. Märtensson, Photoemission, autoionization, and X-ray absorption spectroscopy of ultrathin-film $\mathrm{C}_{60}$ on Au(110), Phys. Rev. B 49, 10717 (1994).

[5] T.-C. Chiang, G. Kaindl, and T. Mandel, Layerresolved shifts of photoemission and Auger spectra from physisorbed rare-gas multilayers, Phys. Rev. B 33, 695 (1986).

[6] D.E. Eastman, T.-C. Chiang, P. Heimann, and F. Himpsel, Surface core-level binding-energy shifts for GaAs (110) and GaSb (110), Phys. Rev. Lett. 45, 656 (1980).

[7] F.J. Himpsel, P. Heimann, T.-C. Chiang, and D.E. Eastman, Geometry-dependent Si $(2 p)$ surface core-level excitations for Si (111) and Si (100) surfaces, Phys. Rev. Lett. 45, 1112 (1980).

[8] J. Cazaux, About the charge compensation of insulating samples in XPS, J. Electron. Spectrosc. Relat. Phenom. 113, 15 (2000).

[9] A. Rosengren and B. Johanson, Calculated transitionmetal surface core-level binding-energy shifts, Phys. Rev. B 22, 3706 (1980).

[10] R.E. Watson, J.W. Davenport, M.L. Perlman, and T.K. Sham, Madelung effects at crystal surfaces: Implications for photoemission, Phys. Rev. B 24, 1791 (1981).

[11] J. Grigas and E. Talik, Splitting of X-ray photoelectron spectra in incommensurate ferroelectric $\mathrm{TIInS}_{2}$ crystals, Phys. Status Solidi B 237, 494 (2003).

[12] V.M. Fridkin, Ferroelectric Semiconductors (Consultants Bureau, New York, 1980) p. 220.
[13] J. Grigas, Microwave Dielectric Spectroscopy of Ferroelectrics and Related Materials (OPA Gordon and Breach, Amsterdam, 1996) p. 336.

[14] S. Kvedaravicius, A. Audzijonis, N. Mykolaitiene, and J. Grigas, Soft mode and its electronic potential in SbSI-type crystals, Ferroelectrics 177, 181 (1996).

[15] J. Grigas, Splitting of the soft mode in a double well potential of SbSI crystals, Ferroelectrics 226, 51 (1999).

[16] K. Lukaszewicz, A. Pietraszko, J. Stepien-Damm, and A. Kajokas, Crystal structure and phase transitions of the SbSI, Polish J. Chem. 71, 1852 (1997).

[17] J. Grigas, E. Talik, and V. Lazauskas, Splitting of the XPS in ferroelectric SbSI crystals, Ferroelectrics 284, 147 (2003).

[18] C.C. Roothaan, New developments in molecular orbital theory, Rev. Mod. Phys. 23, 69 (1951).

[19] S. Huzinaga (ed.), Gaussian Basis Sets for Molecular Calculations (Elsevier, Amsterdam, 1984) p. 426.

[20] E. Clementi (ed.), Modern Techniques in Computational Chemistry (ESCOM, Leiden, 1991) p. 533.

[21] M.W. Schmidt, K.K. Baldrige, J.A. Boatz, S.T. Elbert, M.S. Gordon, J.H. Jensen, S. Koseki, N. Matsunaga, K.A. Nguyen, S. Su, T.L. Windus, M. Dupuis, and J.A. Montgomery, General atomic and molecular electronic structure system, J. Comput. Chem. 14, 1347 (1993).

[22] J. Grigas, E. Talik, and V. Lazauskas, X-ray photoelectron spectroscopy of $\mathrm{Sb}_{2} \mathrm{~S}_{3}$ crystals, Phase Transitions 75, 323 (2002).

[23] M.E. Lines and A.M. Glass, Principles and Application of Ferroelectrics and Related Materials (Clarendon Press, Oxford, 1977), p. 140.

[24] J. Grigas, E. Talik, and V. Lazauskas, X-ray photoelectron spectra and electronic structure of $\mathrm{Bi}_{2} \mathrm{~S}_{3}$ crystals, Phys. Status Solidi B 232, 220 (2002). 


\title{
FEROELEKTRINIO PUSLAIDININKIO SbSI KRISTALU RÖNTGEN'O FOTOELEKTRONU SPEKTROSKOPIJA
}

\author{
J. Grigas ${ }^{\text {a }}$, E. Talik ${ }^{\text {b }}$, V. Lazauskas ${ }^{\text {c }}$

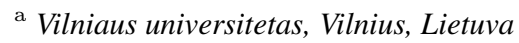 \\ b Silezijos universitetas, Katowice, Lenkija \\ ${ }^{\mathrm{c}}$ Vilniaus universiteto Teorines fizikos ir astronomijos institutas, Vilnius, Lietuva
}

\section{Santrauka}

Pateikti feroelektrinio puslaidininkio SbSI kvazivienmačiu monokristalų Röntgen'o spinduliais sužadintų fotoelektronų valentinès juostos (VJ) ir (110) bei (001) plokštumu svarbiausiu gilių lygmenu spektrai 215-390 K temperatūros srityje. Fotoelektronų sužadinimo šaltinis buvo $\mathrm{Al} K_{\alpha} 1486,6 \mathrm{eV}$ monochromatinè spinduliuotè. Sužadintų fotoelektronų spektrai matuoti nuo 0 iki $1400 \mathrm{eV}$ energijos srityje. Eksperimentiškai išmatuotos fotoelektronų energijos vertès yra palygintos su teorinių ab initio skaičiavimų rezultatais kristalo paraelektrinès ir feroelektrinès fazès paviršiaus ir tūrio atomams. Apskaičiuota ir eksperimentiškai pa- tvirtinta kristalo VJ sandara abiejose fazèse. Nustatyti Sb, S ir I atomu cheminiai poslinkiai. Parodyta, kad paviršiaus ir tūrio atomu fotoelektronų ryšio energijos vertès yra skirtingos. Pirmą kartą eksperimentiškai pastebètas ir teoriškai patvirtintas ypatingai didelis $(3-5 \mathrm{eV})$ paviršiaus atomu gilių lygmenu ryšio energijos poslinkis tūrio atomų ryšio energijos atžvilgiu nuo (001) kristalografinès plokštumos. Ištirta feroelektrinio fazinio virsmo itaka valentinès juostos sandarai ir gilių lygmenu spektrams. Aptariami fotoelektronų ryšio energijos pokyčiai dèl temperatūros, šviesos, kristalografinès krypties ir kristalo savaiminès poliarizacijos. 